\title{
Assessment of nutritional status indicators in children under five at Al-Hamdaniya District, North of Iraq
}

\author{
Anwar K. Matee*, Asma A. Al-Jawadi**
}

* M.sc. Candidate, **Department of Community Medicine, College of Medicine, University of Mosul.

(Ann. Coll. Med. Mosul 2011; 37 (1 \& 2): 71-79).

Received: $16^{\text {th }}$ Mar 2011; Accepted: $10^{\text {th }}$ Oct 2011.

\begin{abstract}
Objectives: To provide a data base for nutritional assessment indicators among children under five in Al-Hamdaniya district, North of Iraq.

Materials and Methods:

Study design: A cross sectional study.

Study setting: The present study was carried out in 3 primary health care centers. These are: AlHamdaniya primary health care center which has a population size in the catchment area of 38310 , Bartella primary health care center (41029) and Al-Namrood primary health care center (25466). These centers are located in Al-Hamdaniya district in Nineveh Governorate, North of Iraq which has an overall population of 180980 .
\end{abstract}

Study participants: Under five children who were brought to the chosen primary health care centers for vaccination purposes.

Outcome measures: Anthropometric measurements (weight and height/length) and WHO growth standard charts were used to compute the nutritional assessment indicators. Age and sex of the examined children were tested as a demographic attributes affect the study indicators.

Results: A total of 775 under five children were included in this study; of this sample, $41.4 \%$ were less than 6 months old, $53.3 \%$ were males. The prevalence of stunting, under weight, wasting, risk of over weight, over weight and obesity were $7.9 \%, 3.7 \%, 2.5 \%, 12.9 \%, 3.0 \%$ and $0.5 \%$, respectively. Stunting is significantly prevalent at age group $24-<60$ months with no sex difference. Wasting showed the same association with age group $0-<6$ months. Risk of over weight, over weight and obesity were significantly present among children $24-<60$ months old and among males.

Conclusion: The present study provides a base line data for nutritional assessment indicators among under fives in a local community in Iraq.

Keywords: Under nutrition, under fives, stunting, under weight, wasting, obesity.

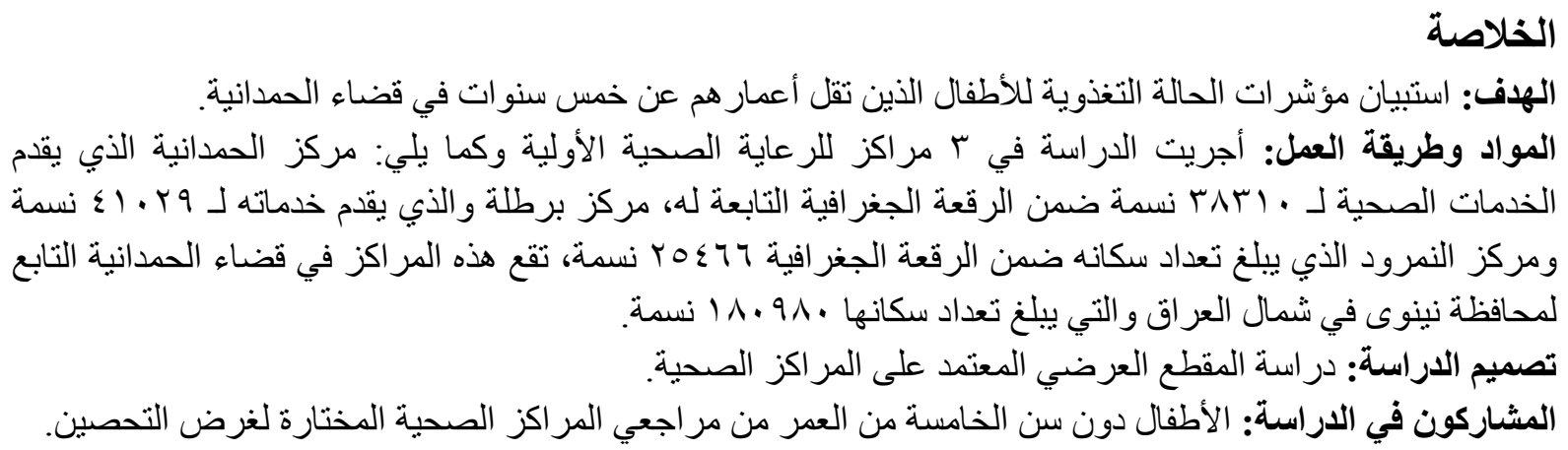


المحصلة النهائية: تم الاعتماد على الوزن والطول منسوبين للعمر والجنس وحيث تمت مقارنتهما مع مخطط النمو

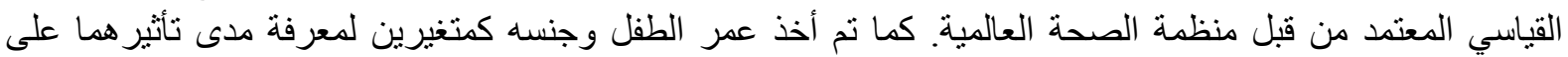
مؤشر ات الدراسة.

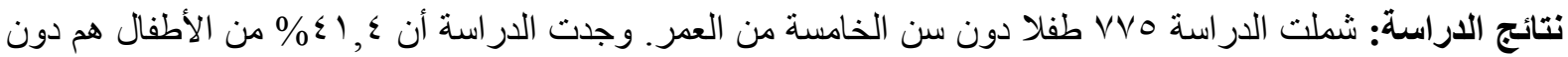

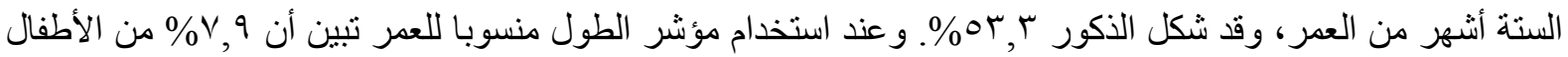

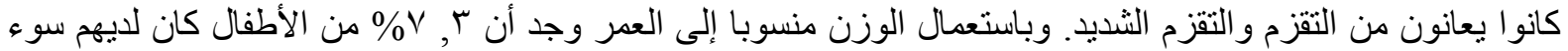

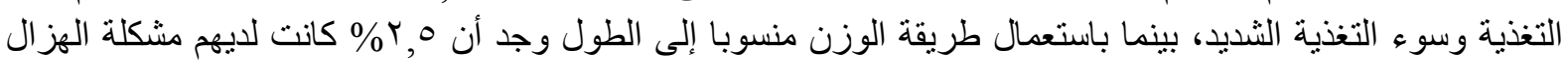

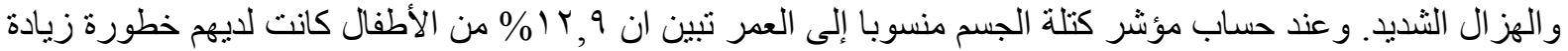

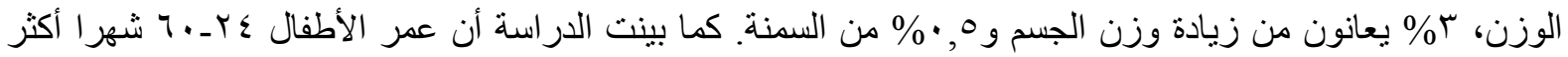

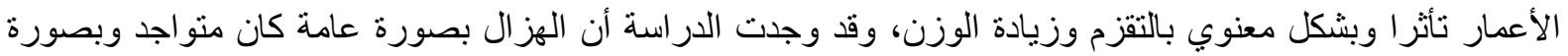

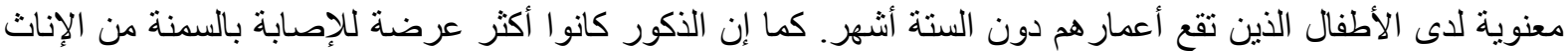
وبتأثير معنوي أيضا. الاستتتاج: وفرت هذه الدر اسة قاعدة معلومات لمؤشر ات التحري التغذوي في قضاء الحمدانية والتي يمكن الاستفادة منها في إنشاء وتطوير برنامج على المستوى الوطني وذللك للمر اقبة المستمرة للحالة التغذوية للأطفال دون سن الخاء الخامسة.

$\mathrm{T}$ he World Health Organization (WHO) defines malnutrition as "the cellular imbalance between supply of nutrients and energy and the body's demand for them to ensure growth, maintenance, and specific function ${ }^{(1)}$. Contrary to the common use, the term malnutrition refers not only to deficiency states, but also to excess or imbalance in the intake of calories, proteins and/or other nutrients ${ }^{(2)}$. Developing nations are not exempted from the upward secular trend in the pandemic of obesity. Obesity is now considered by $\mathrm{WHO}$ as the biggest unrecognized public health problem ${ }^{(3)}$. The prevalence of obesity in some developing countries has reached even higher levels than in many industrialized nations ${ }^{(4)}$.

Stunting can coexist with underweight or with overweight/obesity ${ }^{(5)}$. In the line of coexistence of stunting and overweight in children, these are risk factors for chronic diseases in adulthood ${ }^{(6,7)}$. Management of many chronic diseases that may develop due to the increased incidence of obesity would be beyond the capacity of many nations ${ }^{(8)}$. It is equally important to identify the coexistence of both under nutrition and over nutrition, as an intervention that is designed to prevent only one problem could exacerbate the other ${ }^{(5,9)}$.

Growth indices in the form of length/height for age, weight for age, weight for height, and body mass index (BMI) for age are important tools for the assessment of nutritional status of children. The prevalence of nutritional indicators in the form of stunting, underweight, wasting, risk of overweight, overweight, and obesity in children under 5 years of age is one of the ways of assessment of nutritional status of the population and used as a nutritional surveillance indictors among this age group. ${ }^{(10)}$

Concerning length/height for age; it can help identify children who are stunted (short) or severely stunted due to prolonged under nutrition or repeated illness (chronic malnutrition). While weight for age; it is used to assess whether a child is underweight or severely underweight. On the other hand weight for length/height is especially useful in situations where children's ages are unknown (e.g. refugee situations). It helps identify children with low weight for height who may be wasted or severely wasted (acute malnutrition). Beside that, BMI for age is an indicator that is especially useful for screening for risk of overweight, overweight and obesity (11).

Surveillance of these indicators is commonly practiced regularly in many countries as a measure of public health status ${ }^{(10)}$. The concept of nutritional surveillance is derived from disease surveillance which means to watch over the nutritional status of the 
population in order to make decision that lead to improvement of their health ${ }^{(12)}$. Concerning this issue Mason and Mitchell ${ }^{(12)}$ have defined three objectives, primarily in relation to problems of malnutrition in developing countries to aid long-term planning in health, to provide input for program management, and to give timely warning of the need for intervention to prevent critical deterioration in food consumption.

Accordingly, the aim of the present study is to provide a data base for some nutritional status assessment indicators which are considered as a backbone for nutritional surveillance of children less than 5 years in Al- Hamdaniya District, which is a part of Nineveh governorate in Iraq.

\section{Materials and methods}

Prior to data collection, an official permission was obtained from Nineveh Health Directorate (NHD) to facilitate data collection from the Primary Health Care Centers (PHCCs) that were involved in this study. In addition informed oral consent was obtained from the concerned PHCCs managers, workers, and attendants.

\section{Study setting, design and sampling method}

This study was conducted in Al-Hamdaniya district, which is one of the largest districts in Nineveh Governorate, on the south east of Mosul city. This district has a total population of 180980 , with an estimated number of 30767 children less than five years age ${ }^{(13)}$.

In the present study the target population was children less than five years of age attending the chosen PHCCs with their mothers or care givers for immunization. To achieve the aim of the present study, a crosssectional clinic based design was adopted. Multistage cluster sampling technique was carried out, in which Al-Hamdaniya district was divided into three main sub-districts upper, middle and lower ${ }^{(13)}$. From each sub-district one main PHCC which has the largest catchment's area was selected. Therefore, the selected centers were: Al-Hamdaniya PHCC which has a population size in the catchment area of 38310, Bartella PHCC (41029) and AlNamrood PHCC $(25466)^{(13)}$. In this study minimum sample size approximation was done according to the method used by Gorstein et al., of calculation of sample size in crosssectional studies ${ }^{(14)}$.

The ultimate sample size calculated was 744 children. In this survey the total number collected was 775 . Such figure was distributed among the chosen PHCCs taking the proportion of children under five years in each catchment's area into consideration. In each $\mathrm{PHCC}$, selection of children was carried out by circular sampling in which the start was made randomly and every third thereafter was selected in a circular manner until the total sample size was reached from the target PHCC. ${ }^{(15)}$

Data collection was carried out by interviewing mothers of the target children using a standard questionnaire form. In order to assess the reliability of the information derived from the mothers, a pilot sample consisted of 50 mothers who were interviewed by using a test and re-test approach where two different interviewers were used. The reliability index was calculated (16) which is the percentage of agreement number of mothers during test and re-test occasions. The calculated reliability index was $85.0 \%$.

To assess the validity of the questionnaire form a modified Angoff method was used ${ }^{(17)}$ in which the questionnaire form was reviewed by a committee consisted of seven experts in the field of community medicine, family medicine, and medical statistics from the Department of Community Medicine - College of Medicine/ University of Mosul. Each one of the experts gave his standpoints about the Coverage, Clarity and Reality of the contents of the form. The overall percent agreement among the experts was $88.3 \%$ which indicates that the form is valid.

The included items were chosen from multiple modules $(11,14,18)$. However, some modification was done according to the feedback from the pilot study and stand points of the scientific panel in the Department of Community Medicine. From the related modules, questions about age and sex of the child, and father's job were used in order to determine social class of the target child ${ }^{(18)}$. 
Also there were questions about residence whether the family resides in the center of the district i.e. the city of Karakush, which is considered an urban region while the outside vicinity is rural. Migration status whether migrant (those who are reported in the Migration Office) or non migrant.

\section{Outcome measures and statistical analysis}

Weight in $\mathrm{Kg}$, length/height in $\mathrm{cm}$, age and sex data were used to calculate z-scores i.e. standard deviation score (SDS) of the different nutritional indicators. Age was determined by months (exact age). Baby was weighted with minimum amount of clothing and the result was rounded to the nearest 50 grams. Measurements were carried out using WHO/Seca scale for infants and children. The scales were checked for zero error daily.

Length/ Height was taken without shoes using wooden board for height measurements and plastic board for length measurement, both of them are of WHO/Seca, and the figure was rounded to the nearest centimeter.

Identification of underweight, stunting, wasting, risk of over weight, over weight, and obesity among study sample was calculated using the published WHO child growth standards (19). After plotting results of anthropometric measurements to the reference population in WHO growth standard ${ }^{(11)}$, each of the four anthropometric nutritional status indicators were expressed in standard deviation score from the median of this reference population, which is called (z-score). The child was categorized either as stunted, underweight, wasted or has risk of overweight, overweight or obesity The prevalence of moderate and severe underweight was defined as the proportion of children whose weight for age was below -2 and -3 (SDS), respectively. Similarly, the prevalence of moderate and severe wasting and stunting was defined as the proportion of children with weight for height (wasting) or height for age (stunting) who were below -2 and -3 (SDS). Finally, the prevalence of risk of overweight, overweight and obesity was defined as the proportion of children whose BMI for age was more than $+1,+2$, and +3 (SDS), respectively (11)

Data collection was started on $1^{\text {st }}$ of November, 2010 and ended on the $31^{\text {st }}$ January, 2011.

Data entry and analysis were done using MINITAB version 13. SPSS package version 12 was also used for statistical analyses. Chi squared test was used to determine the presence of association between variables. Odd ratio and its $95 \%$ confidence limit interval $(95 \% \mathrm{Cl})$ were also computed.

\section{Results}

A total of 775 children aged $0-<60$ months were enrolled in this study; of the total sample $53.3 \%$ were males and $46.7 \%$ were females. Almost two fifth $(41.4 \%)$ fell in the age group 06 months and $16 \%$ were $24-<60$ months old. The sample was predominantly rural $(70.0 \%)$. Regarding migration status, $20.8 \%$ of study children were of migrant families. Concerning social class, two thirds of study sample fell in social class III $(33.4 \%)$, and $36.5 \%$ in social class IV.

Table 1 reveals that $7.9 \%, 3.7 \%, 2.5 \%$ of examined children were stunted, under weight, and wasted respectively. While, $12.9 \%, 3.0 \%$ and $0.5 \%$ of the total children included in the survey were presented with risk of over weight, over weight and obesity, in that order. Four children only showed combination of stunting and obesity.

Table 2 demonstrates distribution of study subjects according to the nutritional assessment indicators by age and sex during study period. In regard to male sex the fraction of stunting is minimum at the age group $6-<12$ month $(8.6 \%)$, in female the lowest proportion is at the age group $12-<24$ months $(11.5 \%)$. Underweight is highly prevalent among males and females whose age was $0-<6$ month $(50.0 \%$ and $57.8 \%)$ respectively. Similar trend is shown in wasting. At the same time the present survey found that almost half $(46.8 \%)$ of males with risk of over weight, overweight and obesity were at the age group of $-<6$ month old. While one third $(31.3 \%)$ of females were at the same age group. 
Table (1): Database of nutritional status assessment indicators among study population.

\begin{tabular}{|l|c|c|c|c|c|}
\hline \multicolumn{1}{|c|}{ Indicators } & Malnutrition type & $\begin{array}{c}\text { Malnourished } \\
(\text { No. })\end{array}$ & $\begin{array}{c}\text { Normal } \\
(\text { No.) }\end{array}$ & $\begin{array}{c}\text { Total } \\
\text { (No.) }\end{array}$ & $\begin{array}{c}\text { Overall } \\
\text { prevalence (\%) }\end{array}$ \\
\hline height/age & Stunting & 61 & 714 & 775 & 7.9 \\
\hline weight/age & Underweight & 29 & 746 & 775 & 3.7 \\
\hline weight/height & Wasting & 19 & 756 & 775 & 2.5 \\
\hline BMl/age & Risk of overweight & 100 & 675 & 775 & 12.9 \\
\hline BMl/age & Overweight & 23 & 752 & 775 & 3.0 \\
\hline BMl/age & Obese & 4 & 771 & 775 & 0.5 \\
\hline
\end{tabular}

Table (2): Distribution of study sample according to age, sex and nutritional status assessment indicators.

\begin{tabular}{|l|c|c|c|c|c|c|c|c|}
\hline \multirow{2}{*}{ Age } & \multicolumn{2}{|c|}{ stunting } & \multicolumn{2}{c|}{ underweight } & \multicolumn{2}{c|}{ wasting } & \multicolumn{2}{c|}{$\begin{array}{c}\text { Risk of overweight, } \\
\text { overweight and obesity }\end{array}$} \\
\cline { 2 - 9 } & Male & Female & Male & Female & Male & Female & Male & Female \\
\hline $0-<6$ & $11(31.4)$ & $10(38.5)$ & $5(50.0)$ & $11(57.8)$ & $8(66.7)$ & $4(57.1)$ & $37(46.8)$ & $15(31.3)$ \\
\hline $6-<12$ & $3(8.6)$ & $4(15.4)$ & $2(20.0)$ & $4(21.1)$ & $2(16.7)$ & $2(28.6)$ & $10(12.7)$ & $10(20.8)$ \\
\hline $12-<24$ & $11(31.4)$ & $3(11.5)$ & $3(30.0)$ & $0(00.0)$ & $1(8.3)$ & $0(00.0)$ & $14(17.7)$ & $12(25.0)$ \\
\hline $24-<60$ & $10(28.6)$ & $9(34.6)$ & $0(00.0)$ & $4(21.1)$ & $1(8.3)$ & $1(14.3)$ & $18(22.8)$ & $11(22.9)$ \\
\hline Total & $35(100)$ & $26(100)$ & $10(100)$ & $19(100)$ & $12(100)$ & $7(100)$ & $79(100)$ & $48(100)$ \\
\hline
\end{tabular}

The significance of certain age and sex categories which affect study indicators are shown in Table 3. Statistical analysis of the results demonstrated that children with $24-<60$ months carried a significant risk of stunting when compared with the reference age group (age group with lowest prevalence), (OR: 4.11, 95\% C.I for OR: $1.669-10.119, p=<0.001)$.

Table (3): Association of age and sex with nutritional status assessment indicators.

\begin{tabular}{|c|c|c|c|c|c|}
\hline Category & Significance & stunting & underweight & wasting & $\begin{array}{c}\text { Risk of over weight, } \\
\text { over weight and } \\
\text { obesity }\end{array}$ \\
\hline \multirow{3}{*}{$\begin{array}{l}\text { Age } \\
0-<6\end{array}$} & OR & 1.59 & 2.76 & 3.58 & 1.44 \\
\hline & $95 \% \mathrm{Cl}$ OR & $0.66-3.82$ & $0.79-9.66$ & $1.01-12.85$ & $0.83-2.50$ \\
\hline & $p$-value* & $=<0.296$ & $=<0.097$ & $=<0.037$ & $=<0.199$ \\
\hline \multirow{3}{*}{$6-<12$} & OR & ---- & 1.99 & 2.16 & ---- \\
\hline & $95 \% \mathrm{Cl}$ OR & ---- & $0.49-8.09$ & $0.48-9.79$ & --- \\
\hline & $p$-value* & ---- & $=<0.330$ & $=<0.307$ & ---- \\
\hline \multirow{3}{*}{$12-<24$} & OR & 2.12 & ---- & $\begin{array}{ll}--- \\
\end{array}$ & 1.26 \\
\hline & $95 \% \mathrm{Cl}$ OR & $0.83-5.39$ & --- & ---- & $0.67-2.35$ \\
\hline & $p$-value* & $=<0.108$ & ---- & ---- & $=<0.476$ \\
\hline \multirow{3}{*}{$24-<60$} & OR & 4.11 & 1.69 & ---- & 2.48 \\
\hline & $95 \% \mathrm{Cl}$ OR & $1.67-10.12$ & $0.37-7.71$ & ---- & $1.32-4.66$ \\
\hline & p-value* & $=<0.001$ & $=<0.49$ & ---- & $=<0.004$ \\
\hline \multirow{3}{*}{$\begin{array}{l}\text { Sex } \\
\quad \text { male } \\
\text { Female }\end{array}$} & OR & 1.20 & 0.47 & 1.63 & 1.57 \\
\hline & $95 \% \mathrm{Cl}$ OR & $0.71-2.03$ & $0.21-1.02$ & $0.64-4.21$ & $1.06-2.32$ \\
\hline & p-value* & $=<0.505$ & $=<0.053$ & $=<0.304$ & $=<0.023$ \\
\hline
\end{tabular}

${ }^{*}$ Chi-square test was used.

The blank boxes referred to reference group (age group with lowest prevalence) used in the calculation of odds ratio. 
The lower prevalence of under weight among males $(34.0 \%)$ demonstrates that they are evidently protected from risk of under weight. On the other hand children $0-<6$ month old showed significant risk for the development of wasting $(\mathrm{OR}=3.58, \quad 95 \% \quad \mathrm{C} . \mathrm{l}=1.01-12.845$, $\mathrm{p}=<0.037$ ).

What is more, the result of analysis showed that children who were $24-<60$ months old were at a significant risk of over weight, over weight and obesity (OR=2.481, 95\% C.I=1.320-4.661, $\quad p=<0.004)$. Males sex presents the same picture $(\mathrm{OR}=1.57,95 \%$ C.I $=1.061-2.321, p=<0.023)$.

\section{Discussion}

Knowing the prevalence of stunting, underweight, wasting, and over weight is important for determining the overall health status of the community ${ }^{(20)}$.

In developing countries and marginalized groups in affluent societies, under nutrition is increasing as a result of the debt crisis and consequent economic adjustment policies. On the other hand, the rapid growth of some economies and changes in lifestyles, including diet and physical activity patterns, contribute to other malnutrition problems at the other end of the spectrum ${ }^{(5)}$.

Al-Hamdaniya district is one of the largest districts of Nineveh Governorate in the North of Iraq. It showed many changes after possession in 2003. Before that it was a small town, but the last events that occurred in Iraq especially forced migration lead to an increase in its population size with its adverse effect on the health of the people particularly children under five years of age. Ever since, such population group is the most vulnerable subset that may be affected by abnormal conditions. Fairly, Al-Hamdaniya district did not suffer from the events that affect the rest of the country after possession. Consequently, this district was chosen as a study setting for this work.

The design of this study is a cross-sectional. This has many advantages as it is easy to conduct, needs less time and measure the prevalence of an event which highlights the extent of the problem in the community. Along side, the main characteristics of the affected person are detected, and could be related to disease occurrence ${ }^{(16)}$.

The present study found that $7.9 \%$ of children were stunted, $3.7 \%$ were under weight, $2.5 \%$ were wasted, and $16.4 \%$ was with risk of over weight, over weight and obesity. Corresponding figures reported by the rapid assessment carried out by the UNICEF ${ }^{(21)}$ in Baghdad during 2003 were $15.9 \%$ for stunting, $13.2 \%$ under weight and $7.7 \%$ of examined children were wasted. If results of the present study compared with that of WHO in $2010^{(22)}$ : a different figures were reported which were $27.5 \%$ for stunting, underweight $7.1 \%$ and $15 \%$ for over weight. This is probably due to differences in sample size and different population distribution. Fifteen years ago a study was conducted by Al Jawadi ${ }^{(23)}$ at Mosul city showed that $37.9 \%$ of children were stunted and the prevalence of wasting was $19.7 \%$, these higher figures were most probably caused by the effect of economic sanction and material blockade applied by U.N on Iraqi people at that time. Three years later and at the same city a similar study was carried out showed a lower figures than that used by Al-Jawadi ${ }^{(23)} \quad(10 \%$ and $18.9 \%)$ respectively ${ }^{(24)}$.

Regarding age and sex of the examined children, they are important demographic variables and are the primary basis of demographic classification in the survey. The findings of the present work showed that children in the age group $24-<60$ months were significantly at higher risk of stunting compared with children in the younger age category (6$<24$ months); similar results was shown a decade ago by Al-Jawadi ${ }^{(23)}$ in Mosul city. In addition to it is consistent with other study carried out by Yimer ${ }^{(25)}$ in Ethiopia, and other fare away developing countries such as India (26). The second year of life is a critical period for under nutrition, because the child is dependent on someone for nutritional intake, complimentary foods are introduced, and the child is exposed to food-born pathogens ${ }^{(27)}$. The result of this survey highlights the first two years of life as the most critical period for intervention suggesting an urgent need to institute programs which improve the 
nutritional status of most vulnerable children in the study area. Such programs are probably most effective if they are instituted among children in the first three years of life.

Cross-sectional study conducted by Rao et al., ${ }^{(28)}$ in North-East India in 2004, has been shown that female children were at higher risk of stunting than male children. Other studies showed boys were more malnourished than girls such as that carried out by Malla and Shrestha ${ }^{(29)}$ in Nepal, and by El Mouzan et al., ${ }^{(30)}$ in Saudi Arabia. The present study revealed no significant gender difference in the prevalence of stunting. The same result has been reported by Schoenbaum et al., ${ }^{(31)}$ in Gaza Strip in 1995. While under weight so called general malnutrition seems to be evidently more prevalent in females, with males being evidently protected yet this relationship is of no significant value, this result unlike the results in the study of $\mathrm{EI}$ Mouzan and his co-workers ${ }^{(30)}$ in Saudi Arabia; who reported an increasing fractions of under weight with increasing age this paradoxical findings may be attributed to different study locality, design and sample size.

Regarding wasting, it reflects the proportion of achieved body mass to chronological age and is particularly sensitive to acute growth disturbance. This measurement is used in less developed areas where age assessment is difficult. The result of this study showed that wasting was significantly more prevalent among children < than 6 months old (OR=3.58, 95\% C.l=1.01-12.845, $p=<0.037$ ), probably due to the repeated attacks of common infection during this period. A similar finding was reported by Anderson et al., ${ }^{(32)}$ in Ghana.

On the other hand the results of BMI for age measurement showed that $16.4 \%$ of children suffered from risk of over weight, over weight or obesity. This figure is higher than that reported by the study of Tinh and Nhan ${ }^{(33)}$ in Viet Nam, who examined a smaller number of children $(n=270)$ with quite varied nutritional environment. In the present study over weight and obesity estimates were $3.5 \%$ unlike that of WHO $(15.0 \%)$ which covered a ten years period (1999-2009) ${ }^{(22)}$. This dissimilarity is probably due to change in the life style, dietary habits and increased time of watching television and computer games among older age groups.

The high prevalence of obesity problem with statistical significance at age group 24-60 months needs further attention as obese child will become obese adult, Pediatric obesity has been documented in low and middle income communities (LMICs) and is the driving force behind pediatric metabolic syndrome risk that has become a growing public health concern in such settings ${ }^{(34)}$. It is associated with health problems for the child/adolescent including discriminating risk of psychosocial morbidity, cardiovascular complications, and type 1 and type 2 diabetes ${ }^{(35)}$.

\section{Conclusion and recommendation}

This study has helped in determining the nutritional status indicators of under five children in Al-Hamdaniya district. These data can be used as a baseline for the development of local and national nutritional surveillance system.

\section{References}

1. World Health Organization. Malnutritionthe Global Picture. WHO. http://www.who. int/home-page/. [cited 2010 Dec 10].

2. Blossner Monika, De Onis M. Malnutrition : Quantifying the Health Impact at National and Local Levels. WHO Environmental Burden of Disease. Series No. 12, 2005; 7-8.

3. James PT, Leach R, Kalamara E, Shayeghi M. The worldwide obesity epidemic. Obes Res 2001; 9 (4): 228-33.

4. World Health Organization. Obesity: Preventing and Managing the Global Epidemic. Report No.894, 2000; 23-28.

5. Doak CM, Adair LS, Bentley M, Monteiro C, Popkin BM. The dual burden household and the nutrition transition paradox. Int $\mathrm{J}$ Obes 2005; 29:129-36.

6. Frenk J, Bobadilla J, Stern C, Frejka T, Lozano R. Elements for a theory of the health transition. Health and Social Change in International Perspective Boston. 1994; 25-49. 
7. World Health Organization. Reducing risk, Promoting Healthy Life. The World Health Report: Geneva: WHO; 2002. 98-122.

8. Moore TR. Adolescent and adult obesity in women: a tidal wave just beginning. Clin Obstet Gynecol 2004;47:884-9,980-1.

9. Uauy $\mathrm{R}$, Kain J. The epidemiological transition: need to incorporate obesity prevention into nutrition programmes. Public Health Nutr 2002; 5:223-9.

10. De Onvs M, Monteiro C, Akrı J, Glugston G. The worldwide magnitude of proteinenergy malnutrition: An overview from the WHO Global Database on Child Growth. Bull World Health Organ 1993; 71:703-12.

11. World Health Organization. Training Course on Child Growth, WHO Child Growth Standards, Interpreting Growth Indicators. WHO, Geneva; 2008: 13-14.

12. Mason JB, Mitchell JT. Nutritional surveillance. Bull World Health Organ 1983; 61(5): 745-55.

13. Nineveh Health Office. Primary Health Care Department. Al-Hamdaniya Primary Health Care Sector; 2010.

14. Gorstein J, Sullivan KM, Parvanta I, Begin F. Indicators and Methods for CrossSectional Surveys of Vitamin and Mineral Status of Population. The Micronutrient Initiative (Ottawa) and the Centers for Disease Control and Prevention (Atlanta); 2007:125-128.

15. Indrayan A, Sarmukaddam SR. Medical Biostatistics. New York. Basal, Marcel Dekkar. Inc. 2001: 77: 422-425.

16. Gordis L. Epidemiology. $3^{\text {rd }}$ edition. Philadelphia: WR Sandars Company; 2004: 120-130,137-139.

17. Donne WA, Armato RP: Supportive data and guidelines for using Angoff, Ebel and Nedelsky cutoff score methods. In International Personnel Management Association Assessment Council (IPMAAC) Conference: 1997 June. Newport Beach.

18. Al-Yousbaki DB. Cultural Sociology For Health and IIIness. Mosul, Iraq: Dar Ibn AlAtheer; 2007: 90.

19. WHO. Multicentre Growth Reference Study Group. WHO Child Growth
Standards: Length/height-for-Age, Weightfor-Age, Weight-for-Length, Weight-forHeight and Body Mass Index- for-Age: Methods and Development. Geneva; 2006.

20. Bloss E, Wainaina F, Bailey RC. Prevalence and predictors of underweight, stunting, and wasting among children aged five and under in western Kenya. J Trop Pediatr 2004; 50:260-70.

21. Nutrition Research Institute, Ministry of Health, UNICEF. Rapid Nutrition Assessment for Children under five years of Age in Baghdad Governorate. 2003.

22. WHO. World Health Statistics. 2010:103111.http://www.who.int/whosis/EN_WHS1 0_Full.pdf. [cited 2011 Jan 2]

23. Al-Jawadi AA. Under fives nutrition five years after the blockade. Ann Coll Med Mosul 1996; 22(1, 2): 36-45.

24. Al-Rashedi MW. Assessment of malnutrition of children under five years of age in Al-Thawra District/Mosul. DPH Dissertation, Community Medicine Department, College of Medicine, Mosul University, Iraq; 1998: 24-26.

25. Yimer G. Malnutrition among children in southern Ethiopia: Levels and risk factors. Ethiop J Health Dev 2000; 14 (3):283-292.

26. Kumar D, Goel NK, Mittal PC, Misra P. Influence of infant-feeding practices on nutritional status of under-five children. Indian J Pediatr 2006; 73(5):417-421.

27. Neumann CG, Harrison GG. Onset and evolution of stunting in infants and children. Examples from the Human Nutrition Collaborative Research Support Program. Kenya and Egypt studies. Eur J Clin Nutr 1999; 48(1):90-102.

28. Rao GR, Ladusingh L, Pritamjit R. Nutritional status of children in north-east India. Asia Pac Pop J 2004; 19(3):39-56.

29. Malla S, Shrestha SM. Complementary Feeding Practices and its Impact on Nutritional Status of under Two Old Children in Urban Areas of the Kathmandu, Nepal. JNHRC 2004; 2(1):14.

30. El Mouzan MI, Foster PJ, Al Herbish AS, Al Salloum AA, AI Omar AA, Qurachi MM. 
Prevalence of malnutrition in Saudi children: A community-based study. Ann Saudi Med 2010; 5(30):381-5.

31. Schoenbaum M, Tulchinsky TH, Abed Y. Gender differences in nutritional status and feeding patterns among infants in the Gaza Strip. Am J Public Health 1995; 85(7): 965-969.

32. Anderson AK, Bignell W, Winful S, Soyiri I, Asiedu MS. Risk factors for malnutrition among children 5-years and younger in the Auapim-north district in the eastern region of Ghana. Curr Res Biol Sci 2010; 2(3):183-188.
33. Tinh $\mathrm{HQ}$, Nhan $\mathrm{NH}$. Using the new World Health Organization standards to assess the nutrition status of Thai preschoolers in Yen Bai province, Viet Nam. Proceedings 09 2010; 107-110.

34. Kelishadi R: Childhood overweight, obesity, and the metabolic syndrome in developing countries. Epidemiol Rev 2007; 29:62-76.

35. Reilly JJ, Methven E, McDowell ZC, Hacking B, Alexander D, Stewart L, Kelnar CJ. Health consequences of obesity. Arch Dis Child 2003; 88(9):748-752. 